\title{
Além da alfabetização: perspectivas históricas da experiência moçambicana de alfabetização de jovens \\ e adultos
}

\author{
Beyond alphabetization: historical perspectives of the \\ Mozambiquean experience of young and adult \\ alphabetization
}

\section{Au delà de l'alphabétisation: perspectives historiques de l'expérience du Mozambique d'alphabétisation de jeunes et d'adultes}

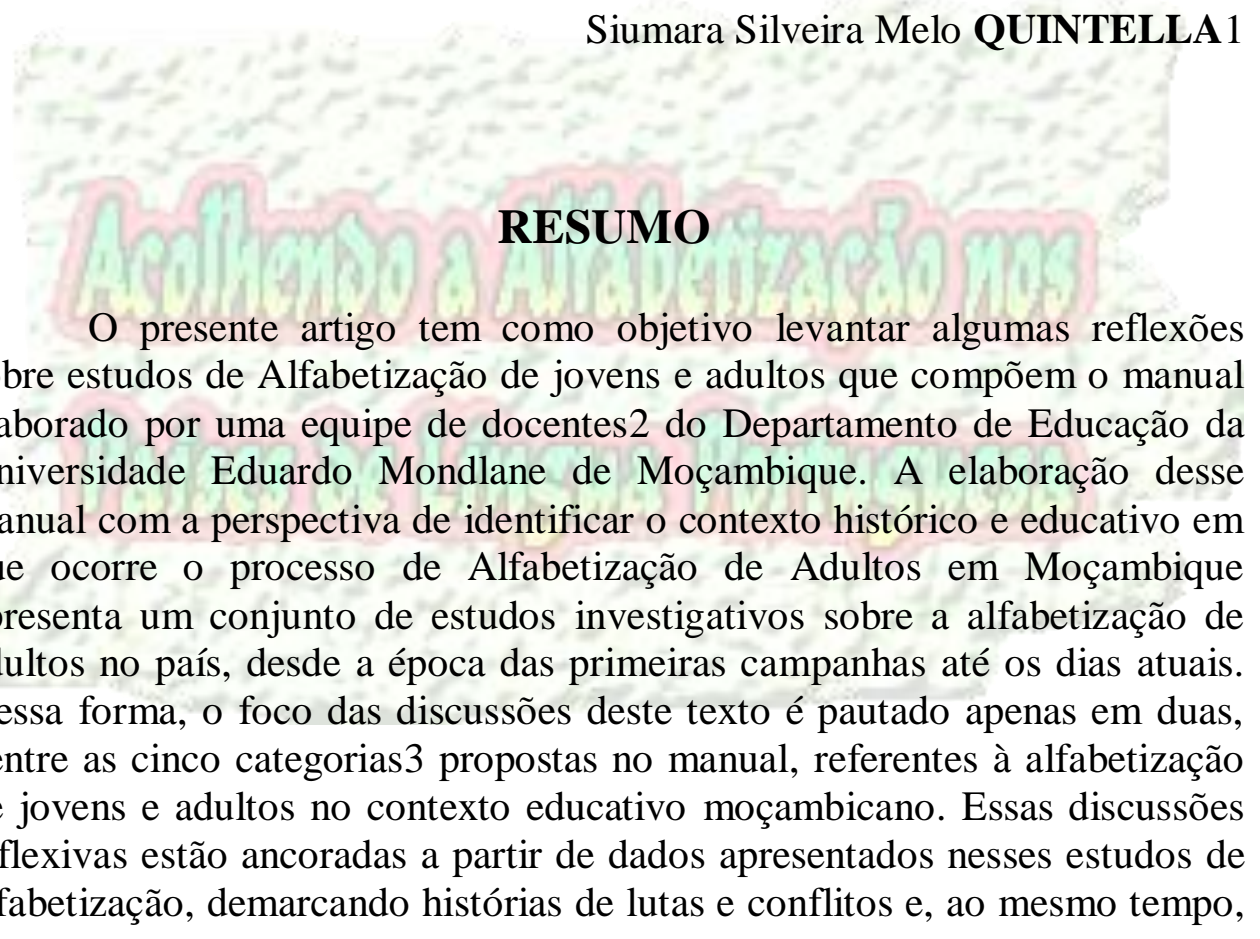

\footnotetext{
1 Mestre em Educação Escolar. Docente e Coordenadora do Curso de Pedagogia das Faculdades Integradas FAFIBE/SP. Coordenadora Pedagógica de Ensino Fundamental e Médio.

O manual foi idealizado e produzido por uma equipe de três docentes, nomeadamente por: Agneta Lind, Alzira Munguambe e Domingos Buquê, e tem como título: "Manual Alfabetização de Adultos em Moçambique.1975 $2006 "$

As autoras explicitam que a concepção do manual não se trata de uma mera compilação de textos. Os treze textos que compõem o manual são divididos em cinco categorias, com as seguintes áreas temáticas: Campanhas de Alfabetização, Alfabetização no local de trabalho, Alfabetização numa perspectiva histórica, Funcionalidade (dos programas) da alfabetização, Avaliação dos Programas de Educação de adultos, com Alfabetização incluída.
} 
apontando novos horizontes voltados para o acesso das classes populares à educação.

Palavras-chave: Alfabetização de jovens e adultos em Moçambique, perspectivas históricas, demandas contemporâneas.

\begin{abstract}
This article has the objective to raise some reflections about studies of young and adult Alphabetization that compose the manual organized by a teachers group of the Education Departament in Eduardo Mondlane Mozambique University. The organization of the manual has the perspective of identifying the studies about Young and Adult Alphabetization in Mozambique and shows a complex whole of investigative studies about the adult alphabetization in the country, since the first programs till nowadays. Thus, the focus of the discussions of this text is based only on two classes among the five proposed in the manual, referring to the young and adult alphabetization in the educative context in Mozambique showing some historical perspectives. These reflexive discussions are based on facts present in the studies of alphabetization, delimiting histories of fights and conflicts and at the same time pointing new horizons to the access of the education by the popular classes.
\end{abstract}

Index terms: young and adult Alphabetization in Mozambique, historical perspectives, contemporary demands.

\title{
RÉSUMÉ
}

Cet article a pour but faire quelques réflexions sur les études de l'alphabétisation de jeunes et d'adultes qui font partie du guide préparé par une équipe d'enseignants du ministère de l'Éducation de l'Université Eduardo Mondlane au Mozambique.

La préparation de ce guide ayant pour objectif identifier le contexte historique et éducatif dans lequel se passe le processus d'alphabétisation des adultes au Mozambique, présente un ensemble d'études de recherche concernant l'alphabétisation des adultes dans le pays, depuis l'époque de la première année de campagne, jusqu'à nos jours .

Ainsi, le centre des discussions du texte est basée sur deux catégories, choisies entre les cinq catégories proposées dans le guide, liées à l'alphabétisation de jeunes et d'adultes dans le contexte de l'éducation au Mozambique. Ces discussions sont ancrées à partir des données présentées dans ces études d'alphabétisation, en pointant les histoires de lutte et de conflit. En même temps, pointant de nouveaux horizons d'accès à ceux qui sont moins bénéficiés à l'éducation. 
Mots clés: Alphabétisation de jeunes et d'adultes au Mozambique, perspectives historiques, besoins contemporain.

\section{ASPECTOS INTRODUTÓRIOS: algumas referências conceituais básicas}

Tropeçando na dor humana, nós nos perguntávamos em torno de um sem-número de problemas. Que fazer, enquanto educadores? Há mesmo o que fazer? Como fazer, o que fazer? Que precisamos nós, os chamados educadores, saber para viabilizar encontros entre mulheres, homens e crianças cuja humanidade vem sendo negada e traída, cuja existência vem sendo esmagada? O futuro é dos Povos e não dos Impérios (FREIRE, 2000, p.76-77).

Com o propósito de partir de uma referência conceitual e adotar uma metodologia de pesquisa bibliográfica de textos significativos que compõem o manual aqui nomeado, o presente artigo busca levantar algumas discussões relacionadas a estudos sobre Alfabetização de Jovens e Adultos de Moçambique (Manual Alfabetização de Adultos em Moçambique-1975 2006. Maputo, 2007), desde a época das primeiras campanhas de alfabetização até as perspectivas atuais.

O foco das reflexões desse texto se delimita em duas áreas temáticas, propostas pelos organizadores do manual, e referem-se às categorias: Campanhas de Alfabetização analisadas por vários autores dentre eles Funchs (1993); e Alfabetização numa perspectiva histórica, que dentre os autores é descrita em forma de relatório por Mouzinho (2002) apresentado na Conferência Internacional sobre Alfabetização e Educação Básica de Adultos na Universidade de Natal, África do Sul, sobre a experiência Moçambicana.

O que se espera, ao desenvolver este artigo, é que a forma de encaminhar as discussões possa levar o leitor a compreender o atual enfoque na alfabetização de jovens e adultos diante da realidade social moçambicana, apontada pelas pesquisas das áreas temáticas citadas. 
Os estudos sobre educação de jovens e adultos vêm ganhando espaço nas discussões do cenário educacional, principalmente, no que se refere à alfabetização.

No contexto contemporâneo, os estudos sobre a alfabetização de jovens e adultos é uma "palavra-chave", no pleno sentido; segundo Freire (1985), é a criação ou a montagem da expressão escrita e da expressão oral que deveriam vir do universo vocabular dos grupos populares, expressando a sua real linguagem, os seus anseios, as suas inquietações, as suas reivindicações, os seus sonhos.

De acordo com o pensamento educacional de Paulo Freire, a leitura do mundo precede a leitura da palavra; por isso, o ato de ler e escrever deve começar a partir de uma compreensão muito mais abrangente do ato de ler o mundo.

Segundo o autor, o movimento do mundo à palavra e da palaviva ao mundo evidenciam ser o conhecimento um processo de relação Homem e mundo; um processo de relação social e política.

Nesse sentido, afirma que o processo de alfabetização:

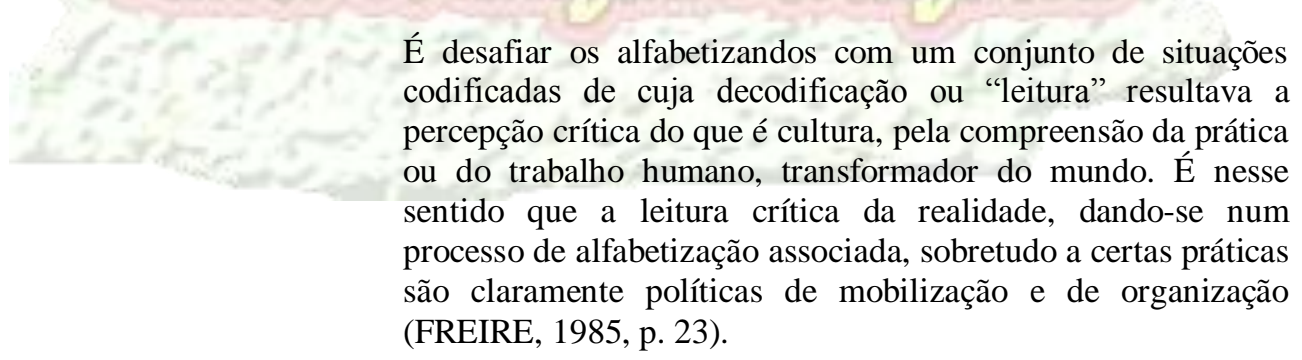

Dessa forma, assevera Paulo Freire que não se pode pensar a prática educativa dicotomizando ler e escrever:

A educação é sempre uma certa teoria do conhecimento posta em prática, e é naturalmente política. Vale dizer: não importa se o projeto é de alfabetização de adultos, ou outro, a prática educativa será mais eficaz quando possibilita aos educandos o acesso a conhecimentos fundamentais ao campo em que se formam e os desafiem a construir uma compreensão crítica de sua presença no mundo (FREIRE, 2000, p. 92). 
A partir dessas afirmações, pode-se dizer que o marco histórico na educação de jovens e adultos se deu a partir das contribuições de Paulo Freire. Posteriormente, vários autores têm abordado a questão da alfabetização de jovens e adultos, centrando suas análises nas práticas educativas, ou seja, discutem a educação de jovens e adultos em novas bases; como: Ribeiro (1999), Tfouni (2001), Piconez (2002), Soares (2002), Skliar (2002) e Pereira (2004).

Soares (2002) defende a indissociabilidade entre o letramento e a alfabetização e a indissociabilidade entre as dimensões individual e social do letramento, ligadas à leitura e à escrita em que os indivíduos se envolvem em seu contexto social. Nesse aspecto, o letramento consiste num procésso mais amplo ao espaço escolar e não necessariamente está condicionado ao sujeito alfabetizado.

O termo letramento surgiu, de acordo com Soares (2002), da necessidade de uma nova maneira de compreender a alfabetização. Para a autora a definição de letramento é o estado ou condição daquele que aprende a ler e a escrever, e isso implicita a idéia de que a escrita traz conseqüências sociais, culturais, políticas, econômicas, cognitivas e lingüísticas tanto para o indivíduo como para todo o grupo social.

Nesse aspecto, ainda afirma Soares (2002), que o termo analfabetismo não explica a problemática da alfabetização, por revelar apenas uma preocupação com o analfabeto, que não tem acesso a uma cultura letrada, grafocêntrica; sem considerar o contexto sócio-cultural no qual se vive.

Skliar (2002, p. 8) associa os termos letramento e minorias ${ }^{4}$, denominando-os de letramentos, que na sua concepção: "é o olhar do letramento a partir de um sujeito, uma(s) sociedade(s), uma(s) cultura(s).

4 O termo "minorias" é utilizado pelo autor como uma expressão que se origina numa experiência especificamente européia. Segundo Skliar, o referido termo tem sua origem nos conflitos nacionalistas no final do século XVII e no começo do século XIX. Nesse contexto, o termo foi utilizado para caracterizar grupos nacionais ou étnicos que iniciaram a viver uma experiência de subordinação por parte de grupos nacionais ou étnicos. 
Uma duplicidade de quem olha e é olhado pelos letramentos, e aos problemas enfrentados nas práticas desenvolvidas no interior das políticas inclusivas".

Tfouni (2001), na tentativa de romper com a divisa alfabetização e letramento, afirma que o letramento é um processo sócio-histórico:

\begin{abstract}
Em uma sociedade letrada, as práticas sociais influenciam todos os indivíduos de uma dada sociedade de maneira pessoal, particular. Entretanto, o letramento focaliza aspectos sóciohistóricos e aquisição de um sistema escrito por uma sociedade, tendo por objetivo investigar não somente quem é alfabetizado, mas também quem não é, fazendo parte, portanto do social (TFOUNI, 2001, p.78).
\end{abstract}

Partindo desses pressupostos teórico-conceituais, pode-se percéber que várias tentativas de implantação de programas de alfabetização para jovens e adultos têm sido realizadas como práticas de inclusão social, fundamentalmente no que se refere aos países pobres em desenvolvimento, dentre eles, os países africanos.

\title{
2. O contexto histórico e social da Educação de jovens e adultos em
}

\section{Moçambique}

Nenhum colonizado, como individuo ou como nação, sela sua libertação, conquista ou reconquista sua dentidade cultural sem assumir sua linguagem, seu discurso e por eles ser assumido (FREIRE, 1987, p. 205).

Na tentativa de problematizar a questão da alfabetização de jovens e adultos em Moçambique, fundamentalmente no que diz respeito ao contexto histórico, social e político em que se deu, Funchs (1993, p. 45) afirma que, o “processo de descolonização nos países asiáticos e africanos elevou o estatuto da alfabetização, tendo-se tornado um meio de modernização e desenvolvimento".

Os estudos da autora, que compõem o manual elaborado pelos docentes da Universidade Eduardo Mondlane, referem-se à situação 
lingüística na África, especificamente em Moçambique, marcada pelo desenvolvimento histórico. Tem-se em vista as conseqüências da dominação colonial portuguesa sofrida pelo país.

$\mathrm{Na}$ sua contextualização, esse estudo aborda as realizações das campanhas de alfabetização desenvolvidas em Moçambique logo depois da independência, uma vez que a guerra civil reduziu as perspectivas de desenvolvimento, colocando o país numa situação econômica deplorável.

Segundo os resultados obtidos por Funchs (1993), esse estudo investigativo, realizado por meio de observação das aulas de alfabetização e análise de documentos relacionados a essas campanhas de alfabetização ${ }^{5}$ ocorridas em Moçambique e Cabo Verde, revela que a prática de alfabetização se desenvolveu durante o período da guerra da libertação e no período posterior à independência com um número significativo de participação de alfabetizandos ${ }^{6}$; e foi se reduzindo ao longo do tempo. De acordo com os dados obtidos, de 87.657 e 119.394 alfabetizados nas duas primeiras campanhas, o número foi para 37.430 aprovados em 1982, ficando reduzido significamente em $50 \%$.

Nesse período, analisa a autora que a alfabetização era vista como veículo de desenvolvimento, de aumento de produção econômiea e integração_política, seguindo modelos europeus; sem considerar a realidade da população.

Essa questão da "alfabetização como pressuposto e meio de desenvolvimento", destacado por Funchs (1993), tem como pano de fundo a ideologia do desenvolvimento, desconsiderando assim a identidade dos alfabetizandos:

\footnotetext{
5 A autora utiliza o termo "Campanha", tratando-se da avaliação da implementação do Sub-Sistema de Educação de adultos (SSEA), cujo início foi em 1983, quando as campanhas já tinham terminado, pois a última foi de meados de fevereiro a meados de novembro de 1982.

${ }^{6}$ A alfabetização conheceu bons resultados durante o período da guerra de libertação e no período pósindependência. A composição das turmas de alfabetização era de adultos politicamente ativos, que trabalhavam em empresas e a maioria possuía conhecimentos de língua portuguesa e certa experiência de escolarização.
} 
A análise da interação pedagógica revela que as aulas consistiam nas respostas em coro as perguntas colocadas pelo alfabetizador, revelando:- uma fraca ligação de experiências e conhecimentos dos alfabetizandos com os conteúdos propostos; - uma educação ideológica baseada na reprodução de idéias, em vez de uma conscientização real na base do conhecimento uma vez que os conteúdos de aprendizagem eram assimilados de forma mecânica, através da memorização, sem nenhuma relação com seu dia a dia (FUNCHS, 1993, p. 48).

Essas constatações vêm ao encontro das críticas apresentadas na proposta de alfabetização por Paulo Freire, que se caracterizam numa prática alfabetizadora dialógica e democrática.

A prática alfabetizadora dialógica e democrática implica reconhecer aos outros o direito de dizer sua palavra e estabelecer ações concretas que permitam a participação. O diálogo em Paulo Freire é compreendido como o momento em que os seres humanos se encontram para conhecer e refletir sobre sua a realidade tal como a fazem e refazem:

Quando suas vozes são ouvidas, é possível perceber nelas as conhecimentos que eles utilizam, o diálogo é uma exigência existencial. E, se ele é o encontro em que se solidarizam o refletir e o agir de seus sujeitos endereçados a ser transformado e humanizado, não pode reduzir-se a um ato de depositar idéias de um sujeito no outro, nem tampouco tornar-se simples troca de idéias a serem consumidas pelos permutantes (FREIRE, 1987, p. 79).

Ātravés de suas falas, é possível pereeber as diferentes linguagens e a preocupação em trazer fatos do cotidiano, estimulando os indivíduos a pensar e não apenas a saber de cor as novas informações, com o objetivo de que reconhecessem e empregassem esses conhecimentos na sua vida diária.

Segundo a análise investigativa do processo pedagógico ${ }^{7}$ apresentado, Funchs (1993) aponta que a ligação entre a alfabetização e o dia-a-dia dos alunos era quase inexistente, tampouco existia sincronia entre os conteúdos e as necessidades efetivas de sua formação. As aulas de

\footnotetext{
7 Segundo Funchs (1993), na investigação empírica realizada em 14 centros de alfabetização, dos quais 9 na província de Nampula e 5 na província de Maputo, foram escolhidos diferentes setores econômicos: indústria (3), setor de prestação de serviços (4), cooperativa agrícola (1) e bairros comunais de povoações médias (2).
} 
alfabetização não consideravam as necessidades de formação dos alfabetizandos e sua língua de comunicação, distanciando-os assim da sua identidade cultural.

Dessa forma, constatou-se, na referida pesquisa, que a cultura oral passava despercebida na planificação, elaboração e realização dos programas de alfabetização:

As condições materiais para a realização das aulas de alfabetização diferiam de centro para centro, as empresas de grandes dimensões tinham salas de aulas apropriadas, enquanto nas empresas agrícolas e bairros de residência as aulas eram dadas ao ar livre, ou em outros lugares improvisados e frequentemente sem meios adequados. As aulas eram bastante formalizadas com uma planificação rigorosa. O materiall de ensino era elaborado na base do método global silábico, e eram propostos diversos exercícios de leitura e escrita (FUNCHS, 1993, p. 47).

Conforme reflete essa autora, diante do cenário educacional moçambicano, faz-se necessário novamente recorrer às críticas de Paulo Freire em relação às práticas educativas pautadas na concepção bancária, que se encontra muito presente nos programas de alfabetização de jovens e adultos. Tem sido um grande desafio rompê-las, no sentido de se criarem formas diferentes de trabalhar, respeitando a voz e os conhecimentos-dos alunos, sem que as aulas se tornem uma simples mẹmorização de conhecimento:

A concepção e a prática "bancárias", imobilistas, "fixistas", terminam por desconhecer os homens como seres históricos, enquanto a problematizadora parte exatamente do caráter histórico e da historicidade dos homens. Por isto mesmo é que os reconhece como seres inacabados, inconclusos, em e com uma realidade que sendo histórica também, é igualmente inacabada. [...] Daí que seja a educação um afazer permanente. Permanentemente, na inconclusão dos homens e do devenir da realidade (FREIRE, 1987, p. 72-73).

Nos resultados apresentados em seu estudo, Funchs (1993) revela que os programas de alfabetização criavam resistência e pouca integração 
dos alfabetizandos. De acordo com os dados levantados, mostra que cerca de $70 \%$ dos alfabetizandos não concluíram a alfabetização, reforçando assim o "sentimento de marginalização".

Esse cenário político e econômico configurado, de acordo com a autora, contribuiu para o fracasso da alfabetização, que não deve ser atribuído apenas à guerra, mas também à política governamental de Educação e às práticas de atuação do Ministério da Educação.

Segundo a pesquisadora, nas suas abordagens conclusivas, os programas de alfabetização não abriam possibilidades de continuação da formação para o alcance de uma formação profissional, contribuindo para o enfraquecimento da sua posição social.

Essa questão implica que:

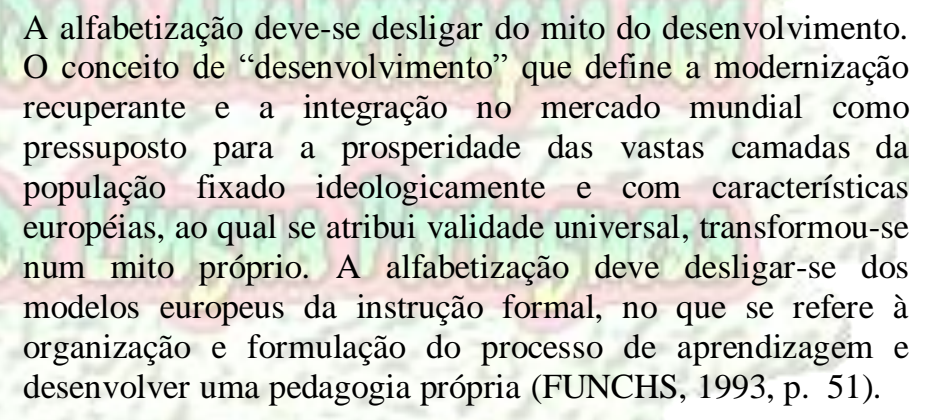

Ainda nas considerações finais, Funchs (1993) retoma os dados apresentados da alfabetização em Moçambique durante a luta de libertação. Assim, reforça-se, nesse período de governo de transição, o alto prestígio do Programa de Alfabetização como processo social importante, uma vez que representava um local de encontro de vários níveis sociais. Com esses dados históricos, as pesquisas revelam que os alfabetizandos tinham maior sucesso onde conscientemente lhes fossem dado lugar para as inter-relações sociais.

\footnotetext{
${ }^{8} \mathrm{O}$ sentido de marginalização é tratado pela autora no seu estudo considerando os discursos em torno do analfabetismo em Moçambique, que reduziam a auto-estima e o poder das pessoas analfabetas e dos próprios alfabetizandos.
} 


\section{3- Perspectivas Históricas: Experiência Moçambicana de alfabetização de jovens e adultos e as demandas contemporâneas}

De acordo com Mouzinho (2002), para uma melhor compreensão do atual enfoque na alfabetização de adultos, é importante considerar os dados estatísticos efetuados pelo Instituto Nacional de Estatística (INE, 2001) com os seguintes percentuais:

Existem 558 unidades de alfabetização e educação básica de adultos $\mathrm{m}$ todo o país. Deste número, 223 (41.7\%) estão localizados na zona norte (Niassa com 24, Cabo Delgado com 75, e Nampula com 134 ), 212 (38\%) estão zona centro (Tete com 64, Manica com 47, Sofala com 89 e Zambésia com 12), e $113(20 \%)$ na região sul do país (Inhambane com 48, Gaza com 20, província de Maputo com 21 e cidade de Maputo com 24) (MOUZINHO, 2002, p. 79).

Segundo o autor, a análise dos dados estatísticos da National Human Development Report (PNUD, 2001) demonstra que à medida em que se avança em direção ao norte do país a oferta de alfabetização tende a abaixar; daí, o resultado indica que a zona sul do país apresenta uma percentagem mais elevada de pessoas alfabetizadas: $65,8 \%$, dos quais, $52,3 \%$ são mulheres; zona centro com $40,9 \%$ dos quais, $23,4 \%$, são mulheres, e, a zona norte, com $30 \%$, dos quais $13,7 \%$ são do sexo feminino.

Esses dados comprovam, segundo Mouzinho (2002), que as
mulheres constituem a maioria da população moçambicana e que o programa de governo tem priorizado ações dirigidas; dentre elas, dinamizar a participação de mulheres e jovens adultas em programas de alfabetização.

$\mathrm{O}$ autor, ao definir a alfabetização no contexto educativo moçambicano, afirma que:

A alfabetização é vista não só como o processo de aquisição de noções básicas de leitura, escrita e cálculo, mas também como uma atividade que estimula e promove a participação do sujeito em atividades sociais, políticas e econômicas, e que lhe dê acesso a uma educação contínua ao longo da vida (MOUZINHO, 2002, p. 76). 
Essa definição vem ao encontro das discussões de Tfouni (2001), que trata a educação de jovens e adultos a partir da concepção de letramento:

O termo analfabetismo não bastava por ser uma preocupação com o analfabeto, aquele que não pode exercer plenamente seu direito de cidadão. A partir do momento em que a concepção de letramento passou a ser propagada, passamos a nos preocupar com essa nova realidade social. O letramento não é somente um problema lingüístico, mas uma questão social e política (TFOUNI, 2001, p.81).

Nessa direção, Mouzinho (2002) expõe aspectos do relatório apresentado com questões programáticas e organizacionais, que apresentam um conjunto de áreas prioritárias no âmbito de Estratégia Nacional com ações a serem desenvolvidas no programa de governo no período de 2001 2005, demonstrando, assim, tentativas para romper essa concepção de alfabetização, nomeadamente: o acesso, qualidade e desenvolvimento Institucional:

Promoção do acesso aos programas de Alfabetização de jovens e adultos e Educação Não formal (AEA-ENF); mobilização e retenção da mulher nos programas de AEA-ENF; desenvolvimento curricular; formação e capacitação de educadores, alfabetizadores, gestores, planificadores, supervisores e avaliadores; educação para a prevenção e combate ao HIV/SIDA; desenvolvimento da capacidade institucional; articulação e parceria com a sociedade civivil e outras instituições do Estado, ensino superior e organizações internacionais; incremento/garantia de financiamento (MOUZINHO, 2002, p. 81-82).

Nesse contexto, o citado autor moçambicano, ao apresentar um quadro das possíveis ações a serem realizadas, aponta as demandas contemporâneas elencadas, delineando um processo de implementação de programas de Alfabetização e Educação de Adultos em Moçambique.

Seguindo o fio da discussão, esse delineamento do processo mostra, a partir dos dados estatísticos levantados, a especificidade da realidade educativa moçambicana quanto à alfabetização e educação de jovens e adultos; que vem ao encontro mais uma vez das idéias de Tfouni (2001), em que adverte sobre a necessidade de estudos sobre práticas e eventos de 
letramento desenvolvidos para a criação de políticas específicas voltadas para a qualidade da educação de jovens e adultos.

Mouzinho (2002) apresenta as demandas contemporâneas, conforme algumas investigações qualitativas e quantitativas trazidas nesse texto referentes a Alfabetização e Educação de Adultos, como desafios que requerem, segundo o autor, uma reflexão profunda, anunciando assim, perspectivas históricas favoráveis; dentre elas, a mobilização do jovem e da mulher moçambicana e a definição de uma política lingüística que seja adequada à natureza multicultural e multilíngüe do país.

Essa reflexão recomendada pelo autor passa pela compreensão de que o objetivo de atendimento educacional de jovens e adultos deve ser reconstruído sob a orientação de novas bases sociais, políticas, econônicas e culturais, com a participação da sociedade civil em todos os níveis, tais como organizações não governamentais internacionais, instituições confessionais, associações comunitárias e demais instituições vocacionàdas a essa questão social.

$\mathrm{Na}$ visão do Mouzinho (2002), essas perspectivas denominadas históricas são caracterizadas por um processo dinâmico e multifacetado de mobilização popular, para as tarefas de reconstrução nacional, de construção da unidade nacional e de afirmação da identidade moçambicana; distanciando-se, assim, do analfabetismo e da pobreza - fatores que flagelam a sociedade moçambicana.

\section{CONSIDERAÇÕES FINAIS}

As questões suscitadas representam a tentativa de levantar algumas reflexões sobre os dilemas, avanços e paradoxos da história e da construção social dos programas de alfabetização de jovens e adultos em Moçambique, pautada por uma história de conflitos sociais, políticos, econômicos e ideológicos. 
Nas perspectivas históricas levantadas pelos estudos investigativos de Funchs (1993) e de Mouzinho (2002), pode-se perceber a busca da ressignificação da Alfabetização e da Educação de Adultos com o desenvolvimento de ações estratégicas que têm sido realizadas, representa tentativas em corresponder às demandas da sociedade moçambicana.

Esse movimento sócio-histórico se deu no processo de descolonização nos países africanos, especificamente em Moçambique, com um discurso pedagógico voltado para o acesso das classes populares à educação, tendo como referencial o modelo europeu.

Funchs (1993) atribui à política governamental e educacional o enfraquecimento dos programas de alfabetização frente ao cenário político e econômico da guerra civil e do período pós-independência; enquanto Mouzinho (2002) aponta perspectivas históricas que ressaltam o contexto educativo moçambicano e o programa de governo no período de 2001 a 2005, com a implementação de um plano estratégico de alfabetizaçã̉o e educação de jovens e adultos.

Assim, a contribuição do Manual idealizado e produzido pela equipe de docentes da Universidade Eduardo Mondlane congrega, num só conjunto, estudos valiosos, em um período histórico da História da Alfabetização de Adultos Moçambicana (1975-2006); por meio de um corpus significativo e relevante, oportunizando se tornar objeto de estudo e de reflexão; no dizer da equipe, "para todos os pesquisadores cuja área de atuação é a alfabetização".

Não se tem, por meio deste artigo, a pretensão de se esgotar essa temática; no entanto, houve-se como objetivo provocar algumas discussões no sentido de se levantar o fenômeno histórico e ideológico da alfabetização moçambicana abordado em novas bases e concepção, tais como: letramento e participação coletiva de vários segmentos da sociedade civil. Toma-se, mais uma vez, as advertidas palavras de Paulo Freire, postas em discussão 
neste artigo e deixadas nestas considerações conclusivas, por meio das seguintes reflexões:

A educação problematizadora, que não é fixismo reacionário, é futuridade revolucionária. Daí que seja profética e, como tal, esperançosa. Daí que corresponda à condição dos homens como seres históricos e à sua historicidade. Daí que identifique com eles como seres mais além de si mesmo - como "projetos" - como seres que caminham para frente, que olham para frente... como um modo de melhor conhecer o que está sendo, para melhor construir o futuro. [...] O profetismo e a esperança que resultam do caráter utópico de tal forma de ação tornado-se a utopia como a unidade inquebrantável entre a denúncia e o anúncio. Denúncia de uma realidade desumanizante e anúncio de uma realidade em que os homens possam ser mais. Anúncio e denúncia não são, porém, palavras vazias mas compromisso histórico (FREIRE, 1987, p. 73).

Recomenda-se a leitura desse manual, que, pela sua natureza, oferece estudos investigativos com categorias temáticas, definindo concepções, práticas e políticas de alfabetização, de relevância para as discussões sobre Alfabetização de jovens e Adultos, permitindo assim, ùma interlocução com pesquisadores de diferentes países.

\section{Referências bibliográficas}

FREIRE, Paulo (1987). Pedagogia do Oprimido. Rio de Janeiro: Paz e Terra.

(2000). Pedagogia da Indignação: cartas pedagógicas e outros escritos.São Paulo:Editora UNESP.

LODI, Ana Cláudia et al (2002). Letramento e Minorias. Porto Alegre: Mediação.

FUNCHS, E. (1993). Alfabetização: Desenvolvimento de potencialidades ou reforço da Marginalidade? Alfabetização em Moçambique e em 
CaboVerde na sua relação com formas de comunicação e necessidades da formação nas zonas rurais. In: Manual Alfabetização de Adultos em Moçambique-1975 -2006. Maputo, 2007. p. 44-52.

MANUAL ALFABETIZAÇÃO DE ADULTOS EM MOÇAMBIQUE1975 -2006. Maputo, 2007.

MOUZINHO, Mário (2002). A Experiência Moçambicana de Alfabetização e Educação de Adultos: Relatório Nacional apresentado na Conferência Internacional sobre Alfabetização e Educação Básica de Adultos, Universidade de Natal, África do Sul. In: Manual Alfabetização de Adultos em Moçambique-1975 -2006. Maputo, 2007. p. 75-84.

PEREIRA, Maria Lúcia (2004). A construção do Letramento na educação de Jovens e Adultos. Belo Horizonte: Autêntica.

PICONEZ, Stela (2002). Educação escolar de jovens e adultos. Campinas/São Paulo: Papirus.

RIBEIRO, Vera Masagão (1999). Analfabetismo e atitudes: pesquisá com jovens e adultos. Campinas/São Paulo: Papirus.

SKLIAR, Carlos. (2002). A pergunta pelo outro da língua; a pergunta pelo mesmo da língua. In: LODI, Ana Cláudia (Org.). Letramento e Minorias. Porto Alegre: Mediação. p. 5-11.

SOARES, Magda (2002). Letramento: Um tema em três gêneros. Belo Horizonte: Autêntica.

TFOUNI,--Eeda-(2001). Letramento e Alfabetização. São Paulo: Cortez. 


\section{Autora}

\section{Siumara Silveira Melo Quintella ${ }^{9}$}

Faculdades Integradas Fafibe - Bebedouro - SP

Contato: siumara@mdbrasil.com.br

\section{Como citar este artigo:}

QUINTELLA, Siumara Silveira Melo. Além da alfabetização: perspectivas históricas da experiência moçambicana de alfabetização de jovens e adultos. Revista ACOALFAplp: Acolhendo a Alfabetização nos Países de Língua portuguesa, São Paulo, ano 4, n. 7, 2009. Disponível em: <http://www.acoalfaplp.net>. Publicado em: setembro 2009.

\section{Recebido em outubro de 2008. I Aprovado em novembro de 2008.}

9 Mestre em Educação Escolar. Docente e Coordenadora do Curso de Pedagogia das Faculdades Integradas FAFIBE/SP. Coordenadora Pedagógica de Ensino Fundamental e Médio. 